\title{
A Body of Knowledge and Pedagogy for Global Engineering
}

\author{
Evan Thomas \\ Mortenson Center in Global Engineering \\ University of Colorado Boulder \\ Boulder Colorado 80303 \\ evan.thomas@colorado.edu
}

James Harper

Mortenson Center in Global Engineering

University of Colorado Boulder

Boulder Colorado 80303

james.harper@colorado.edu

Rita Klees

Mortenson Center in Global Engineering

University of Colorado Boulder

Boulder Colorado 80303

rita.klees@colorado.edu

Amy Javernick-Will

Mortenson Center in Global Engineering

University of Colorado Boulder

Boulder Colorado 80303

amy.javernick@colorado.edu

\author{
Carlo Salvinelli \\ Mortenson Center in Global Engineering \\ University of Colorado Boulder \\ Boulder Colorado 80303 \\ carlo.salvinelli@colorado.edu \\ Laura MacDonald \\ Mortenson Center in Global Engineering \\ University of Colorado Boulder \\ Boulder Colorado 80303 \\ laura.a.macdonald@colorado.edu
}

\author{
Gunars Platais \\ Mortenson Center in Global Engineering \\ University of Colorado Boulder \\ Boulder Colorado 80303 \\ gunars.platais@colorado.edu \\ Karl Linden \\ Mortenson Center in Global Engineering \\ University of Colorado Boulder \\ Boulder Colorado 80303 \\ karl.linden@colorado.edu
}

\begin{abstract}
Global engineers must be taught to consider the historical and present causes of persistent poverty and systemic barriers to prosperity. Such training will better inform the choices engineers make and help move the engineering sector away from a product and community-level focus towards working to address the root causes of poverty. A framing for Global Engineering has recently been proposed by the Mortenson Center in Global Engineering at the University of Colorado Boulder, building on over 15 years of curricular efforts. Global Engineering, as taught by the Mortenson Center, positions the field as a complement to Global Health and Development Economics while further embracing a historically contextualized and anti-colonial training.
\end{abstract}

Index Terms - curriculum, learning objectives, pedagogy.

\section{INTRODUCTION}

The role of engineers in contributing to global poverty reduction and in achieving the Sustainable Development Goals is evolving. Typically, the engineer's role in addressing these challenges has been confined to community-, regional-, or national-scale service 
interventions and technology design and development. However, after fifty years of such approaches, overhalf the world's population still lives on less than $\$ 5.50$ a day, ${ }^{1}$ the global burden of disease in low-income countries is overwhelmingly attributable to environmental health issues, ${ }^{2}$ and climate change is already negatively impacting people, most significantly in low- and middle- income settings. Conventional engineering approaches are largely inappropriate given the structural constraints and global drivers that perpetuate poverty. The emerging field of Global Engineering can help address these issues as a discipline that educates students to be prepared to solve engineering and science problems within the socioeconomic, environmental and political constraints often encountered in lower-resource settings ${ }^{3}$. These global engineers can then develop and validate methods, tools, and standards that are broadly useful to the private, public and non-profit sectors. Global engineers must be taught to consider the historical and present causes of persistent poverty. Such training will better inform the choices engineers make and help move the engineering sector away from perceiving poverty as a stage toward inevitable growth that can be helped along with conventional technical solutions and toward addressing systemic barriers to prosperity.

Several approaches for training engineers to engage in global poverty reduction have been proposed, including the "global engineer"4, "development engineering", "humanitarian engineering", and "peace engineering"7. Meanwhile, organizations including Engineers Without Borders-USA, Engineers in Action, and Engineers for a Sustainable World have involved engineering students and professionals in extracurricular and volunteer engagement in developing communities. This approach has been recognized as an important component of professional training ${ }^{8}$. However, there is increasing recognition that this approach is insufficient to train globally responsible engineers ${ }^{9}$ and may unintentionally create opportunities for community exploitation and harm in the name of student training ${ }^{10}$.

A number of universities in the United States have recognized this potential and have established or are working to establish programs in Global Engineering. Toward that end, it has been acknowledged that training globally responsible engineers will require (1) rigor at the curriculum level that is equal to any other engineering discipline, and (2) cross-training engineers with other established development disciplines, including global health, economics, public policy and social business. ${ }^{5}$

Building on these efforts and programs, a framing for Global Engineering has recently been proposed by the Mortenson Center in Global Engineering at the University of Colorado Boulder ${ }^{3}$, building on over 15 years of curricular efforts ${ }^{11}$.

Global Engineering, as taught by the Mortenson Center, positions the field as a complement to Global Health and Development Economics while further embracing a historically contextualized and anti-colonial training. While other programs have chosen modifiers, including "humanitarian" and "development" engineering, the Mortenson Center promotes the term "global" to position the discipline as complement to Global Health while moving away from the "developed / developing" construct or a focus only in humanitarian relief settings. Furthermore, while we recognize that "global engineering" can and is interpreted as inclusive of multinational work among all income settings, as presented in the 2021 UNESCO Engineering Report, "Engineering for Sustainable Development," 12 we 
specialize in supporting engineers and students focused on addressing the particular challenges experienced in low-resource settings anywhere on the globe.

\section{BACKGROUND}

Several engineering educational programs have been developed worldwide in the last two decades that actively aim to provide engineering students with the skills, knowledge and attitudes required to address poverty alleviation and respond to disasters and crises in low-and middle-income countries.

A recent review of 67 engineering programs examined programs with the common goal of preserving life and alleviating human suffering. ${ }^{13}$ Most of the programs have an experiential requirement, such as Project Based Learning (PBL), Service Learning (SL), or study abroad, which represents an opportunity for students wishing to pursue a professional career inthe sector to acquire the required field experience ${ }^{14}$. In addition, SL and PBL have been shown to support student development of the competencies related to the broader context of engineering established by a number of accrediting bodies internationally $y^{9,13}$ and to develop greater self-awareness, cultural sensitivity, teamwork, and empathy ${ }^{10}$.

While the risks are routinely acknowledged, a persistent challenge for educators is ensuring that engineering students are not engaged in an extractive relationship with low-income communities and that the principles described by Sigmon (1979) ${ }^{15}$ are respected. The privilege, power and resources students have often results in beneficial outcomes for the students which are placed before those of the served communities, disempowering communities and promoting neo-colonialist practices ${ }^{10,16}$.

Burleson and Austin-Breneman (2020) ${ }^{17}$ conducted a review of publications by highly active North American researchers associated with both mechanical engineering and civil Engineering for Global Development. The authors found that even within a single discipline and geographic area, degree-granting programs are a growing addition to engineering programs, but there are low levels of consensus on technical terminology and lack of cohesion in the research agenda. Here we identify several example, but not exhaustive, programs to illustrate the breadth of approaches in fields similar to Global Engineering.

The Colorado School of Mines (CSM) in Golden, CO, USA started its Humanitarian Engineering program in 2003 with the goal of creating a culture of acceptance for humanitarian service endeavors, increasing the number of engineering graduates that enter occupations that have a community or international service emphasis and increasing diversity among engineering students and graduates ${ }^{18}$. The program initially offered service learning and internship opportunities, and two minors that balanced technical abilities, economic feasibility, ethical maturity and cultural sensitivity ${ }^{19}$. CSM currently also offers a graduate certificate and Master's program in Humanitarian Engineering with core courses on sustainable community development; community-based research and risks in humanitarian engineering; and three disciplinary tracks focused on sustainable and just use of earth resources: geophysics, environmental engineering and geological engineering ${ }^{20}$. 
The University of California Berkeley offers a master program in Development Engineering, a field that builds on techniques from engineering, development economics, business, information science, behavioral science and sociology with the goal of accelerating the development of low-income communities through a rigorous approach to human-centered design of scalable solutions ${ }^{5,21}$. The program curriculum is T-shaped, providing a broad base of core courses in design, evidence-based assessment techniques, economic development, community engagement, ethics and system thinking, and four concentration areas: artificial intelligence/data analytics for social impact; energy, water and the environment; sustainable design innovations; and healthcare transformations ${ }^{22}$.

The Centre for Global Engineering at the University of Toronto is a multidisciplinary research institute focused on creating evidence-based solutions for vulnerable populations in low-income countries and Canada. Their research is focused on food security, water and sanitation, energy, shelter, education and community capacity building. Educational programs include experiential learning through the participation in capstone projects, and an undergraduate certificate focused on appropriate and innovative technologies and their role in global development ${ }^{23}$.

The University of South Florida (USF) offers an Engineering for International Development graduate concentration that prepares engineering students to work in international development and focuses on issues of sustainability, environment, health, gender, and society. The concentration includes field experience and courses on sustainable development, anthropology and global health ${ }^{24}$.

The breath of offered programs makes it necessary to define methods and approaches to ensure both education outcomes and appropriate and ethical development practices, including internal institutional review, external accountability though involvement in national organizations, and professional recognition though frameworks and accrediting bodies ${ }^{13}$.

An overview of the recent growth and the status of Humanitarian Engineering educational programs in Australasia is presented by Smith et al. 2017 ${ }^{25}$. To support this rapid growth, the Humanitarian Engineering Education Network of Australasia (HEENA) was formed in 2017 and set priority areas to strengthen and further expand the field and its impact including expanding educational research and development, engagement with professional bodies, and advocacy. The Australian Council of Engineering Deans (2018) states that there is a need to professionalize the field of Humanitarian Engineering in order to ensure appropriate practice. The European Universities on Professionalisation on Humanitarian Action (EUPRHA) Project, an initiative that support quality education and ultimately delivery of humanitarian assistance, developed the Humanitarian Action Qualifications Framework, a tool based on learning outcomes that defines different qualification levels throughout the humanitarian sector $^{26}$.

The Royal Academy of Engineering stated that there is a lack of engineers involved in policy-making and strongly recommends increasing the participation of engineers in the early stages of the policy cycle in order to better inform governments' perspective and 
enable engineers to develop solutions with a broader understanding of the challenges to be addressed ${ }^{27}$. An understanding of the workings of government and of the policy making process, the abilities to communicate beyond disciplinary boundaries and to being able to weigh technical and non-technical issues in order to make decisions, and an understanding of the diverse interactions of technology and society, were identified by Mendoza et al. (2012) $)^{28}$ as the main skills and knowledge that enable engineers to participate in public policy. The emerging field of Global Engineering should follow the example of more established fields, such as Global Health and Development Economics, whose professionalization resulted in a high degree of influence in policy ${ }^{3}$.

To professionalize the global development sector and the role that engineers play in it, there is a need to define a body of knowledge (BOK) that identifies the skills and attitudes that engineering students should acquire to be able to improve the sector's practice and impact. In this paper, we propose a BOK for engineers working in global development, building upon the BOK framework developed by the National Society of Professional Engineers which defines an Engineering BOK as, "the depth and breadth of knowledge, skills, and attitudes appropriate to enter practice as a professional engineer in responsible charge of engineering activities that potentially impact public health, safety, and welfare" 29 .

\section{GLOBAL ENGINEERING BODY OF KNOWLEDGE}

The Mortenson Center at the University of Colorado Boulder has evolved from a model of scaling appropriate technology design and implementation to change to a program which emphasizes development and validation of more broadly applicable methods, technologies and evidence generation. As reflected in our recent name change from "Engineering for Developing Communities" to "Global Engineering", we seek to positively impact vulnerable people and their environment by improving development tools and practice.

Our areas of research include the development and validation of water, sanitation, energy, infrastructure and agricultural technologies and methods, design of service delivery models, impact measurement methods and technologies including instrumentation and remote sensing, organizational theory and systems engineering, and development of standards and processes for disaster risk reduction and post-disaster recovery. The Mortenson Center curriculum includes opportunities to take rigorous courses in complementary topics such as Global Health, Development Economics, remote sensing, statistical analysis, and impact evaluation. Our required field practicum embeds students with global development agencies for at least two months, with some students continuing to engage with these agencies for many years.

The Mortenson Center at the University of Colorado Boulder promotes the role and skills of engineers in identifying and addressing the unequal and unjust distribution of access to basic services such as water, sanitation, energy, food, transportation and shelter, and places an emphasis on identifying the drivers, determinants and solutions favoring equitable access.

Through our curriculum, we: 
- Introduce students to the historical causes and present conditions of global inequality, and identify the opportunities and limitations of professional engineering engagement.

- Empower students and working professionals to engage in a historically contextualized, anti-imperial contribution to global engineering.

- Identify and promote the relevance and role of the engineering profession in supporting the reduction of poverty and increasing prosperity.

\section{Program Objectives}

Individuals trained through our academic programs are intended to acquire knowledge andskills derived from internal and external expertise and perceptions of the field of global engineering. Our objectives cover a broad base of core competencies pertinent to all students who are enrolled in either the Global Engineering Undergraduate Program, the Global Engineering Minor, the Graduate Certificate in Global Engineering, the Master of Science in Global Environmental Engineering, or the Master of Science in Global Engineering.

Our Global Engineering Body of Knowledge is intended to supplement the competencies gained through an undergraduate, graduate certificate or graduate degree program in engineering at the University of Colorado Boulder. Our curriculum will not necessarily provide the depth desired for practitioners in every specialty. Further, our approach does not replace the fundamental engineering disciplinary training provided in an accredited undergraduate program; instead, we offer students the opportunity for contextual exposure and specialized skills development relevant to entry-level practitioners in global development. At the undergraduate level, accredited programs may offer a minor in Global Engineering, while at the graduate level programs may be customized for professional training.

Our program objectives are shaped using Bloom's Taxonomy ${ }^{30}$, wherein we identify student outcomes at the levels of mastery, competence, and exposure:

- Mastery of a topic results in the ability to analyze, synthesize, and evaluate situations encountered. Students are capable of adapting their responses to situations in ways that align with these concepts and to explain the importance of following these methodologies to attain the desired outcome.

- Competence in a topic results in the ability to apply the concepts and techniques learned to solve problems in a different way than examples presented. Students value the importance of these topics in a way that consistently exerts influence on their behavior.

- Exposure to a topic results in the ability to recognize terminology and comprehend the concepts being presented. Students learn to value issues and may go on to demonstrate higher level cognitive skills through further study. 
We apply these outcomes across each of our program levels. A consolidated list of primary learning objectives at the graduate certificate level are presented in Table 1 while the complete list at all levels is presented in Appendix 1, Table 2. Our Global Engineering Body of Knowledge student outcomes are then achieved through curriculum offered by the Mortenson Center supporting the learning objectives presented in Appendix 2, Table 3.

\section{TABLE 1}

\section{Graduate CertificAte Primary Learning ObJectives}

1. Analyze the historical and contemporary context of global inequalities and global development poverty alleviation policies, programs, institutions, and social movements.

2. Identify and explain security, public policy, governance and rights-based approaches to global development.

3. Identify and apply relevant engineering skills toward global development.

4. Identify and explain social entrepreneurship applied in global development.

5. Identify and explain the professional field of Global Health.

6. Identify and explain the professional field of Development Economics.

7. Identify and explain systems thinking methods and approaches.

8. Identify and explain project management skills and methods.

9. Implement qualitative and quantitative data collection analysis within a global development application.

10. Apply technical interventions designed to support global development.

11. Apply methods for programmatic impact evaluation.

12. Apply important dimensions of professional field readiness.

13. Recognize cultural differences and apply skills to collaborate across cultures.

14. Function effectively on a team whose members together provide leadership, createa collaborative and inclusive environment, establish goals, plan tasks, and meet objectives.

\section{Program Pedagogy}

The Mortenson Center in Global Engineering includes programming offered at the lower-division undergraduate level, through to professional graduate programs and supporting doctoral research. Figure 1 illustrates several of the undergraduate and graduate pathwaysfor global engineering coursework and credentials. These academic programs are delivered by Mortenson Center faculty and staff, including two dedicated instructors, a full time Managing Director, a Faculty Director, several senior faculty associate directors, and additional staff support. Further, graduate students provide teaching assistance at both the undergraduate and graduate levels, offsetting their own tuition costs. This capacity is enabled through endowments and gifts from the Mortenson Family Foundation; investment by the departments and College of 
Engineering; revenue earned through professional graduate program tuition; undergraduate program resources and externally funded research grants and contracts.

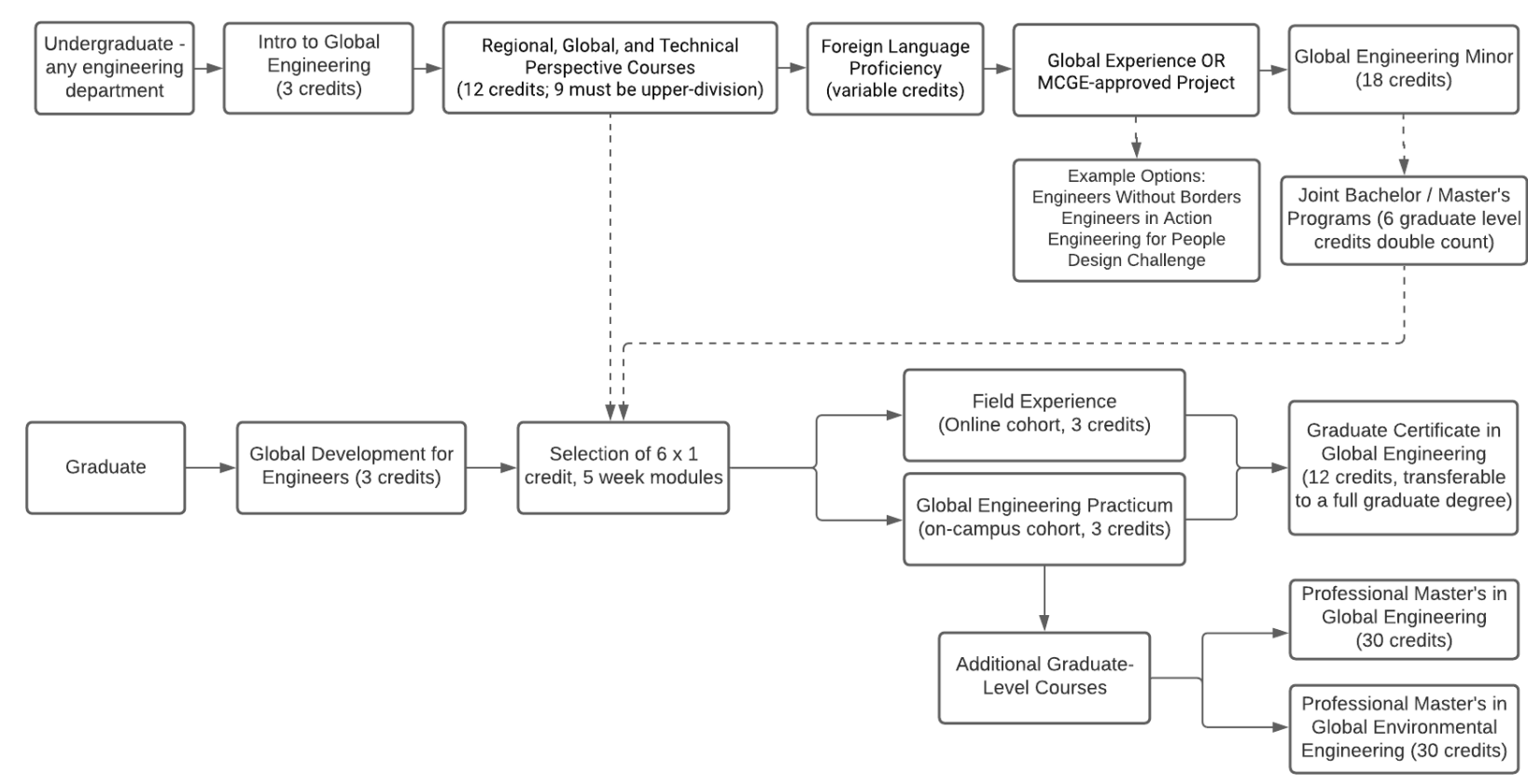

FIGURE 1

SUMMARY OF GLOBAL ENGINEERING PATHWAYS AT THE UNDERGRADUATE AND GRADUATE LEVELS.

\section{Undergraduate Program}

Our undergraduate program is centered around the Global Engineering Residential Academic Program and the Undergraduate Minor in Global Engineering. The core course, Introduction to Global Engineering, is offered through a residential model to first year engineering students and is a prerequisite for undergraduates to enroll in our graduate courses. The Global Engineering Minor requires a total of 15 credits, a demonstration of second-language proficiency, and a project. The courses take an active learning approach which include one-minute essays, class debates, role playing, evening seminars, and extracurricular projects. These projects include mentoring, facilitation and funding support for the student-led Engineers Without Borders-USA and Engineers in Action Chapters, and the Engineering for People Design Challenge.

\section{Graduate Program}

The Mortenson Center graduate program includes a Graduate Certificate in Global Engineering, and two Professional Master of Science degrees. The MCGE Graduate Certificatein Global Engineering is available to any graduate student in the College of Engineeringand Applied Science at CU Boulder. The Professional Masters degree in Global Engineering and the Professional Masters in Global Environmental Engineering 
include all of the same MCGE certificate course offerings, plus the additional support to complete a graduate degree in engineering. Admission into the graduate program requires meeting University of Colorado Boulder College of Engineering and Graduate School admission requirements. In most cases, students have previously earned an undergraduate engineering degree, however some students enter with non-engineering degrees and may be required to take department required prerequisites to enroll in graduate courses.

\section{Field Practicum}

The Global Engineering Field Practicum, a capstone experience for graduate students, is a curricular requirement embedding students with professional organizations. The Mortenson Center has cultivated relationships with a cadre of host organizations for the practicum experience including governmental and non-governmental organizations, consulting firms, and the private sector. Students are placed in well-established organizations for six weeks to six months, depending on their availability and the host organization's needs. Host agencies are selected to match the engineering abilities and interests of the students and cover a range of specialties including Water, Sanitation and Hygiene (WASH), renewable energy, and humanitarian response. Through its practicum program, MCGE links our students with organizations that have local connections and long-term relationships with partner communities. Our students learn from specialists in their sectors, and contribute to building local professional capacity while benefiting from this on-the-job training.

COVID-19 has had a direct impact on the practicum program, requiring that the Fall 2019 cohort complete their practicum experience remotely. The Mortenson Center is preparingfor remote practicum assignments for the Fall 2020 cohort, as well. The ability to adapt to travel restrictions speaks to the history of the program and is reliant on the relationships with host organizations that have been built over the last decade.

\section{Online Delivery}

Starting in Fall 2021, the Mortenson Center will offer a stand-alone online graduate certificatein Global Engineering for students anywhere in the world holding a relevant undergraduatedegree.

\section{Research Engagement}

The Mortenson Center faculty, staff and students practice in the field of global engineering. Expenditures of approximately $\$ 5 \mathrm{M} /$ year are supported through grants and contracts from the National Science Foundation, USAID, NASA, the World Bank, the Millennium Challenge Corporation, the Autodesk Foundation, the Moore Foundation and others. Projects and research include work in drought resilience, drinking water, sanitation, household energy, structures and settlements, remote sensing, instrumentation and impact evaluations. 
Professional staff within the Mortenson Center support faculty in the the management and delivery of these projects, enabling increasing opportunities for doctoral as well as professional masters students to engage in research and practice.

However, research and project opportunities, dependent on external funding, do not generally scale at the same rate as student interest. Therefore, the Mortenson Center works to create value and opportunities for students who may not be participating in formal research.

\section{Extracurricular Programming}

The Mortenson Center supports a number of extracurricular projects and programs, including mentorship of the Engineers Without Borders-USA and Engineers in Action student chapters; sponsoring of engineering capstone projects; and hands-on design and rapid prototyping projects.

\section{Student Recruitment}

The Mortenson Center's graduate education offerings have grown over time, with the Graduate Certificate (12 credits) formally approved in Fall 2010 and the course-based Professional Master's Program (30 credits) initiated in Fall 2014. Recruitment has increased as a result. Prior to these offerings, students could enroll in Engineering for Developing Communities track as part of their degree plan in the Civil, Environmental and Architectural Engineering Department. In the years before the graduate certificate was approved (Fall 2003-Summer 2010), an average of 5 students enrolled in the track each Fall. From Fall 2010 through and including Fall 2020, enrollment has averaged 20 students each Fall, with 27 students matriculating in Fall 2020. The Mortenson Center has experienced an increase in enrollment during the two most recent economic downturns - the 2008 stock market crash and the more recent impact of COVID-19. This indicates that prospective students see value in the graduate program, even - or especially - during times of uncertainty.

The makeup of the incoming cohort has varied over time but has had some consistent trends. Over the past three years, the cohorts have been between 45 and $66 \%$ women and the majority have had undergraduate degrees in engineering. However, recruitment of students outside of civil and environmental engineering has increased over time, with greater interest from students in architectural and mechanical engineering as well as from students with non-engineering backgrounds such as urban planning, international affairs, architecture, geography and community health. The graduate certificate program has a history of attracting students with strong research backgrounds. From 2014 to 2020, seven certificate students have received the NSF Graduate Research Fellowship.

Each cohort often has students who go straight from undergraduate to graduate education while at the same time having students who have been working for 5 years or more since earning their Bachelor's. Many students are fluent in more than one language, and each cohort typically has several international students. However, 
recruitment of students from low- and middle-income countries has remained a challenge in spite of program growth, due in large part to university tuition costs as well as cost of living.

\section{EVAluATION}

\section{Alumni Career Tracking}

Since its first graduates in 2006, the Mortenson Center has prepared its students for careers in non-profit organizations, the private sector, academia and government. Alumni of the Mortenson Center have found work as professional engineers, entrepreneurs, project and program managers, educators, consultants and researchers. A 2020 review of Mortenson Center alumni from 2006 to 2018 found that $27 \%$ of alumni with up-to-date LinkedIn profiles ( $\mathrm{n}=111$ of about 161 graduates) were currently working in global development or a related field. The majority of these alumni completed the graduate certificate, as the first Professional Master's Program students matriculated in Fall 2014. Of the balance of students, 15\% (17) are in executive positions across a range of sectors, including global engineering; and 37\% (41) are working as engineers in sectors outside of global engineering, such as (domestic) water and wastewater treatment, water resources, environmental consulting, international consulting, construction management and municipal government.

Many alumni of the graduate certificate program who also obtained their $\mathrm{PhD}$ from CU Boulder either pursued faculty positions or engaged in policy through the AAAS Science andTechnology Policy Fellowships. The 2020 LinkedIn review of alumni found that 7 of $22 \mathrm{PhDgraduates}(32 \%)$ are in faculty positions, and over two thirds of these faculty were actively teaching courses or conducting research on engineering in lowand middle-income contexts. The remainder were engaged in research adjacent to global development, including climate change and life cycle assessment. From 2012 to 2019, seven MCGE alumni obtained a AAAS fellowship, working in positions at the Department of Energy, Department of State, Millennium Challenge Corporation and US Agency for International Development. Others have continued on to leadership and technical advisor roles in non-governmental organizations such as Water for People, iDE, Bridges to Prosperity, and Save the Children.

As a more general summary, in a Spring 2019 survey of Mortenson Center alumni (distribution $\mathrm{n}=122$, response $\mathrm{n}=33$ ), about $22 \%$ reported having worked for nongovernmental organizations, $19 \%$ for academia or think tanks, $14 \%$ for engineering consulting firms, $12 \%$ for United States or local government agencies, and $10 \%$ for bilateral and US government foreign assistance agencies, among others (participants were asked to select all that applied). Of the development sectors that alumni had worked in, the most common were WASH, water resource management and water security (19\%); global health (12\%); post disaster reconstruction and recovery $(10 \%)$; infrastructure $(8.5 \%)$; and resiliency $(8.5 \%)$. With regards to time spent working or volunteering in global development outside of the Mortenson Center, $71 \%$ had worked or volunteered for more than one year; $43 \%$ for more than two years; and $25 \%$ for 
more than five years.

\section{Advisory Board Guidance}

The MCGE Advisory Board was refreshed in 2018 to broaden the experience base of the advisors to reflect the ambition of the Mortenson Center academic program and to provide guidance on the skills and training required of global engineers. Comparison to the previous board is out of scope of this forward-looking paper, but we describe current board membership: "The advisory board currently includes the CEO of Water For People (a civil and environmental engineer), the CEO of Bridges to Prosperity (a civil and geotechnical engineer and an MBA), the President of Engineering for Change (a mechanical engineer), a PhD development economist at the World Bank (in the water and infrastructure practices), an associate dean for research in International Studies and Programs and former Program Director in the National Science Foundation's Office of International Science and Engineering (a PhD in biochemistry), a professor of global health ( $\mathrm{PhD}$ in environmental health), the CEO co-founder of Conservation X Labs and assistant administrator and founder of the USAID Global Development Lab (PhD in biology and a JD), the Executive Director World Savvy (an education specialist and MS in international affairs), and the former Senior Advisor for Space and Advanced Technologies at the US State Department (a power systemsengineer).

The MCGE Advisory Board guided the development and reviewed the implementation of the body of knowledge and curriculum presented in this paper, in particular reflecting on the primary learning objectives at the graduate certificate level presented in Table 1. The MCGE Advisory Board highly rated learning objectives (Table 1) related to methods and approaches in global development (3), including systems (7), and quantitative and qualitative data collection and analysis (9). Further, the advisors emphasized the importance of project management (8), functioning well on a team (14) and across cultures (13). The Advisory Board has further suggested that skills missing in the body of knowledge and curriculum include greater emphasis on decolonization and equity in development programs, businessand contractual knowledge, and entrepreneurship.

A recurring discussion between MCGE and the Advisory Board has been the tension between specializing in one area of global development, namely water and sanitation, versus building a reputation beyond WASH. Given the limited capacity of MCGE, this discussion continues to be a balance between ambition and capacity, and is often guided more by research opportunities and student interests on a year-to-year basis.

\section{Graduate Student and Alumni Feedback}

Since its inception in 2004, the Mortenson Center has re-evaluated and improved its program's graduate certificate and professional master's degree in Global Engineering to meet the needs of both its students and the evolving field of global engineering ${ }^{3}$. Building upon the 2014 evaluation of $\mathrm{MCGE}^{11}$, this section reviews student perceptions of the program reported via survey from 2015 through 2020 and student 
recommendations to improve the program; describes how the program has changed to address these perceptions; and identifies topics for discussion to improve the program further.

Students agree that the program's faculty; practicum; core class "Global Development for Engineers"; and technical elective "Water, Sanitation and Hygiene in Development" are all strengths of the program. The program continues to include these two courses as important components of its certificate and professional master's degree, and support and hire facultyto maintain high-quality teaching and research.

Over time, the program's course structure and topics; guidance about the practicum experience; and facilities have been markedly improved based on student recommendations. Most notably, in 2018 and 2019, the program re-evaluated its curriculum, hired a new instructor to help develop the program's curriculum, and hired a new faculty director and managing director after two core courses in the program (Sustainable Community Development 2 and Fieldwork Methods) received mixed reviews in 2015-2017. Based on this re-evaluation of the program's curriculum, the program introduced a new one-credit modular course format in Fall 2019 that allows students to select various topic-specific courses to fulfill their MCGE certificate. These new one-credit module courses include Introduction to Development Economics, Program and Project Management, Introduction to Global Health, and Study Design and Impact Evaluation. During this reorganization, the courses Sustainable Community Development 2 and Fieldwork Methods were phased out, and the topics that were covered in those courses were reorganized into two of the new one-credit module courses (Program and Project Management, and Solution Identification and Proposal Development), which were developed by the new MCGE instructor. Students in 2020 agreed that the one-credit modular course format is now a strength of the program but also noteda wide variety of grading rigor and workloads in the new onecredit modular courses.

Students have also requested more research opportunities for certificate students and reduced program cost. Students in the certificate program are generally engaged in research with faculty members in engineering departments who may sponsor their tuition and a stipend. Some of these students work with MCGE core faculty; however, there is not enough research funding or capacity to support all certificate students directly within MCGE.

Professional MS students are generally expected to pay their own tuition and expenses and the degree programs and typically do not include any research-based opportunities. This is consistent with the training approach the University of Colorado Boulder has taken with professional graduate degrees distinct from traditional research based programs.

However, it is common for students to start as a Professional MS student, but seek networking opportunities with faculty to transition in their second year to a compensated research-based graduate degree. In recent years, MCGE has actively communicated this potential pathway. However, some of the responses from these surveys suggest that improved communication of the value proposition of the Professional MS is required, to better manage expectations of students who are paying 
their own way to earn this graduate degree. Realistically, MCGE cannot scale both research opportunities and student funding. MCGE also relies, in part, on earned revenue through student tuition payments. Therefore, the inherent value of the Professional MS must be communicated while still supporting the ambition of students who seek to transition into research supported graduate programs.

Students also requested both greater depth and breadth in course offerings. However, MCGE has also experienced barriers to students participating in more class offerings, namely because their degree programs require a heavy course load. As such, MCGE's existing offerings are often under-utilized. To address these concerns, MCGE is working to increase communication to students around other course offerings available at CU Boulder, including in languages, history, culture, ethnography, and technical skills. Further, MCGE is working across departments to qualify MCGE courses as meeting elective and/or core course requirements at both undergraduate and graduate levels. Students have also requested improvements to the program's new courses, career guidance, the ethnic diversity of its studentand faculty populations.

To continue providing thought-leading education and research in global engineering, the Mortenson Center plans to continue improving its program based on feedback from its students and changes in the field of global engineering to most effectively train engineers to solve problems in low-resource contexts.

\section{CONCLUSIONS AND FUTURE WORK}

Engineers work professionally across development-related institutions including positions based in the United States. These include positions in government, non-profits, donors, universities, and industry. Additionally, many technical professionals are employed in low- resource countries who contribute to and lead global engineering interventions. Therefore, the Mortenson Center curriculum seeks to serve both students originating and/or working in the United States, as well as those originating and/or working in countries that are focal areas for global engineering efforts. To contribute to increasing engineering capacity in low-income countries, MCGE seeks to recruit and retain students from these countries while continuing to support professionalization of this field among US students. As the financial model of the University of Colorado Boulder relies on students paying tuition and externally funded research revenues, supporting international students originating from low- and middle-income countries will remain a capacity limited to a few on-campus students each year. This model contrasts with some programs at other universities that have dedicated scholarship funding to support cohorts of international students. For example, the IHE Delft Institute for Water Education is supported in part by UNESCO and provides scholarships to students from around the world.

In part to address these budgetary limitations, MCGE is currently implementing a recruitment and retention model for the online Graduate Certificate in Global Engineering that would target both working professionals in the United States and those potential students from and working in low- and middle-income countries. As the online certificate program would charge professional graduate tuition, MCGE will have an 
opportunity to offset the cost to LMIC students. This approach will seek to improve diversity and inclusion in our program, and effectiveness in training global engineers. Further, the credits earned through the online program are transferable to an on-campus graduate program.

In spring 2021, MCGE hosted a two-day virtual workshop funded by the National ScienceFoundation designed to develop a consensus body of knowledge and teaching approach for global engineering graduate programs in the United States. This workshop included over120 participants representing 38 universities in North America, each of whom have graduate level offerings in global engineering-related courses and programs, and 18 industry, donor and government partners including representatives from USAID, the Gates Foundation, ASME, Engineers Without Borders-USA, Stantec, TetraTech, and DAI. A consensus BOK is currently in development for publication in 2021. In practice, this consensus BOK could be referenced and adapted by universities in North America and globally when appropriate. This consensus BOK would not supersede areas of emphasis and diversity among university programs but could enable a common framework of educational expectations.

\section{ACKNOWLEDGMeNT}

The Mortenson Center was founded by Professor Bernard Amadei and thanks to the generous support of the Mortenson Family Foundation. We also thank our students, alumni, advisors, partners and affiliated faculty and staff including Robyn Sandekian, Sarah Goodroad, Adria Ryan, Andrew Wingfield, Doug Smith, Keith Molenaar, Rajagopalan Balaji, Avery Bang, Iana Aranda, DeAndra Beck, Andrew Reynolds, Alex Dehgan, Eleanor Allen, Luis Andres, Thomas Clasen, Donna Dalton, Mathias Mortenson and Dana Mortenson. 
International Journal for Service Learning in Engineering, Humanitarian Engineering and Social Entrepreneurship Vol. 16, No. 1, pp. 37-57, Spring 2021

ISSN 1555-9033

\section{ApPendix 1: Program Learning ObJectives}

\section{Table 2: Program Learning Objectives}

\section{Undergraduate - Students graduating with the Mortenson Center Global Engineering Minor or enrolled in the Global Engineering Residential Academic Program will be ableto demonstrate the following:}

Expectation of Competence (apply) - Students will:

- Be able to analyze the historical and contemporary context of global inequalities and global development poverty alleviation policies, programs, institutions, and social movements.

- Be able to identify and apply relevant engineering skills toward global development.

- Have an ability to function effectively on a team whose members together provide leadership, create a collaborative and inclusive environment, establish goals, plantasks, and meet objectives.

Expectation of Exposure (remember, understand) - Students will be able to:

- Recognize and explain technical interventions designed to support globaldevelopment.

- Explain important dimensions of professional field readiness.

- Recognize cultural differences and illustrate skills to collaborate acrosscultures.

- Identify and explain methods for programmatic impact evaluation.

- Identify and explain social entrepreneurship applied in global development.

- Identify and explain qualitative and quantitative data collection analysis within a global development application.

- Identify and explain the professional field of Global Health.

- Identify and explain the professional field of DevelopmentEconomics.

\section{Graduate Certificate - Students graduating with the Mortenson Center Graduate}

Certificate in Global Engineering (online or on campus):

Expectation of Competence (apply) - Students will:

- Be able to analyze the historical and contemporary context of global inequalities and global development poverty alleviation policies, programs, institutions, and social movements.

- Be able to identify and apply relevant engineering skills toward global development.

- Be able to implement qualitative and quantitative data collection analysis within a global development application.

- Have an ability to function effectively on a team whose members together provide leadership, create a collaborative and inclusive environment, establish goals, plan tasks, and meet objectives.

- Be able to apply technical interventions designed to support global development.

- Be able to apply important dimensions of professional field readiness.

- Be able to recognize cultural differences and apply skills to collaborate across cultures.

- Be able to apply methods for programmatic impact evaluation.

Expectation of Exposure (remember, understand) - Students will be able to identify and explain: 
International Journal for Service Learning in Engineering, Humanitarian Engineering and Social Entrepreneurship Vol. 16, No. 1, pp. 37-57, Spring 2021

ISSN 1555-9033

- Social entrepreneurship applied in global development.

- The professional field of Global Health.

- The professional field of Development Economics.

- Systems thinking methods and approaches.

- Project management skills and methods.

- Security, public policy, governance and rights-based approaches to global development.

\section{Professional Masters Degree - Students graduating with the Global Engineering or} Global Environmental Engineering masters degree will be able to demonstrate the following:

Expectation of Mastery (analyze, evaluate, create) - Students will:

- Be able to analyze the historical and contemporary context of global inequalities and global development poverty alleviation policies, programs, institutions, and social movements.

- Be able to identify and apply relevant engineering skills toward global development.

- Be able to apply systems thinking methods and approaches.

- Be able to apply project management skills and methods.

- Have an ability to function effectively on a team whose members together provide leadership, create a collaborative and inclusive environment, establish goals, plan tasks, and meet objectives.

Expectation of Competence (apply) - Students will be able to:

- Apply technical interventions designed to support global development.

- Implement qualitative and quantitative data collection analysis within aglobal development application.

- Recognize cultural differences and apply skills to collaborate across cultures.

- Apply methods for programmatic impact evaluation.

Expectation of Exposure (remember, understand) - Students will be able to identify and explain:

- Social entrepreneurship applied in global development.

- The professional field of Global Health.

- The professional field of Development Economics.

- Security, public policy, governance and rights-based approaches to global development. 
International Journal for Service Learning in Engineering, Humanitarian Engineering and Social Entrepreneurship Vol. 16, No. 1, pp. 37-57, Spring 2021

ISSN 1555-9033

\section{APPENDIX 2: COURSE LEARNING OBJECTIVES}

\section{Table 3: Course Learning Objectives}

\section{Introduction to Global Engineering (Lower Division Undergraduate, 3 credits)}

- Identify the geopolitical and historical context of health and socioeconomic disparities within and between countries.

- Describe global poverty reduction efforts, including historical and present-day programs, frameworks, funding agencies, and implementations.

- Describe and critique technical interventions promoted to address water, sanitation, hygiene, energy, infrastructure, shelter, agricultural, and evaluation needs.

- Design and assess programmatic Theory of Change and evaluation frameworks for global development interventions.

- Criticize the role of professionals, including engineers, in poverty action, including identifying and reducing colonial, imperial and otherwise unjust practices in our professional fields.

Global Development for Engineers (Graduate / Upper Division, 3 credits)

- Examine and discuss legacies, theories, approaches, and debates relative to globaldevelopment from both historical and contemporary perspectives.

- Identify the social, economic, environmental and policy issues shaping the direction of global development.

- Describe the actors that shape the global development agenda and solve global problems.

- Demonstrate cultural and social awareness of global events and perspectives.

- Demonstrate an ability to interact ethically and responsibly with local, national, and global communities.

- Value people, ideas, and activities from other cultures as a means of personal andprofessional development.

- Identify the core principles and practices that ensure global development is sustainable.

- Identify and assess the challenges of cross-cutting issues such as climate change,religion, migration, conflict.

- Identify promising opportunities and innovative tools and approaches from more than one discipline.

- Communicate ideas and values clearly and effectively in multiple contexts, withdiverse audiences, and via appropriate media formats.

\section{Introduction to Global Health for Engineers (Graduate / Upper Division, 1 credit)}

- Identify emergent methods and interventions designed to address global health challenges in developing countries.

- Use the Global Burden of Disease data to describe and interpret health disparities between and among low, middle and high income countries.

Introduction to Development Economics for Engineers (Graduate / Upper Division, 1 credit)

- Demonstrate a broad understanding of the central themes and issues of economic development and growth.

- Recognize poverty, its underlying causes and formulate solutions 
International Journal for Service Learning in Engineering, Humanitarian Engineering and Social Entrepreneurship Vol. 16, No. 1, pp. 37-57, Spring 2021

ISSN 1555-9033

\section{A Systems Approach to Global Engineering (Graduate / Upper Division, 3 credits)}

- The ability to identify the multiple dimensions of engineering projects in a developed or developing country context;

- Be aware of the role non-technical issues may play in their technical decision-making;

- Appreciate the multi-cultural, social, and economic dimensions of practicing engineering;

- Understand the global interconnectedness of issues at different scales from the local to the global and why a systems approach can complement a more traditional linear approach;

- Formulate problems and their solutions in a more systemic and integrated way;

- Be able to approach a wide range of simple, complicated, and complex problems often characterized by different levels of uncertainty.

\section{Program and Project Management (Graduate / Upper Division, sequence of 3 x 1 credit} courses)

- Describe the principles, phases, and challenges of the international developmentproject cycle management.

- Use formats, tools, instruments and procedures employed in planning, implementation and evaluation of international development projects.

- Develop a theory of change, a logical framework and the indicators used to measure progress towards an intervention's outcome achievement.

Global Engineering Methods (Graduate / Upper Division, sequence of 3 x 1 credit courses)

- Discuss international development community appraisal concepts, methods, andchallenges. Implement participatory and ethnographic methods.

- Conduct secondary data collection for a specific topic and context.

- Discuss commonly used impact evaluation designs and the conditions under whicheach may be used.

- Identify the ethical issues that need to be considered when conducting impact evaluations

- Discuss commonly used qualitative and quantitative data collection methods, tools.and challenges

- Employ remote sensing and in-situ data and analysis tools to illustrate the utility of technologies for water, agriculture, global health, and disaster forecasting and relief.

Water, Sanitation and Hygiene (WASH) (Graduate / Upper Division, sequence of 3 x 1 credit courses)

- Identify the social, economic, institutional, and environmental benefits and challenges of providing access to safe drinking water and improved sanitation

- Discuss WASH technical and service delivery options for a variety of settings

- Describe the role of hygiene and behavior change in the WASH sector

- Explain innovative approaches to emerging WASH issues, e.g.COVID 19, climate change, water scarcity.

Humanitarian Aid (Graduate / Upper Division, sequence of 3 x 1 credit courses)

- Describe the global system of humanitarian aid

- Illustrate the opportunities and challenges of the humanitarian-development nexus

- Discuss the theory and practice of the various phases of emergency management

- Criticize colonial and otherwise unjust practices in the humanitarian aid sector 
International Journal for Service Learning in Engineering, Humanitarian Engineering and Social Entrepreneurship Vol. 16, No. 1, pp. 37-57, Spring 2021

ISSN 1555-9033

- Describe the importance of a disaster risk reduction and resilience perspective

- Use mapping and GIS software to conduct a hazard impact scenario analysis

- Develop a disaster risk reduction management plan.

- Identify the factors affecting short and long-term recovery and rebuilding

- Describe shelter and settlement approaches

- Illustrate the current challenges presented by migration, refugees and displacement.

\section{Household energy (Graduate / Upper Division, sequence of 3 x 1 credit courses)}

- Design and assess existing and new household energy services technology used inlow and middle income countries.

\section{Field Practicum (Graduate, 3 credits)}

- Engage in a significant, field-based assignment in a low or middle income setting

- Display MCGE core values while applying the theoretical foundations learned in class to real world work experiences

- Put into practice international perspectives, cultural awareness, ethical reasoning, discipline knowledge, analytical competence, and communication and professional skills to accomplish the host agency's scope of work

- Gain insight into the field of international development.

\section{REFERENCES}

1. The World Bank, Nearly Half the World Lives on Less than $\$ 5.50$ a Day. 2018; https://www.worldbank.org/en/news/press-release/2018/10/17/ nearly-half-the-world-liveson-less-than-550-a-day.

2. Institute for Health Metrics and Evaluation, Global Burden of Disease Compare Tool. 2019; http://vizhub.healthdata.org/gbd-compare.

3. Thomas, E. Toward a New Field of Global Engineering. Sustainability 11 (2019), 3789.

4. Amadei, B. Engineering for Sustainable Human Development: A Guide to Successful Small-Scale Community Projects; ASCE, 2014.

5. Nilsson, L.; Madon, T.; Sastry, S. S. Toward a new field of Development Engineering: Linking technology design to the demands of the poor. Procedia Engineering. 2014.

6. Mitcham, C.; Munoz, D. Humanitarian Engineering. Synthesis Lectures on Engineers, Technology and Society, 2010.

7. Amadei, B. Engineering for peace and diplomacy. Sustainability (Switzerland) 2019.

8. Bourn, D.; Neal, I. The Global Engineer: Incorporating global skills within UK higher education of engineers. Engineers Against Poverty / Development Education Research Center, University of London. 2008.

9. Mintz, K.; Talesnick, M.; Amadei, B.; Tal, T. Integrating Sustainable Development into a ServiceLearning Engineering Course. Journal of Professional Issues in EngineeringEducation and Practice, 140 (2014).

10. Birzer, C. H.; Hamilton, J. Humanitarian engineering education fieldwork and the risk of doing more harm than good. Australasian Journal of Engineering Education, 24 (2019), https://doi.org/10.1080/22054952.2019.1693123.

11. Sandekian, R.; Chinowsky, P.; Amadei, B. Engineering for Developing Communities at the University of Colorado Boulder: A Ten Year Retrospective. International Journal for Service 
International Journal for Service Learning in Engineering, Humanitarian Engineering and Social Entrepreneurship Vol. 16, No. 1, pp. 37-57, Spring 2021

ISSN 1555-9033

Learning in Engineering, Humanitarian Engineering and Social Entrepreneurship, Special Issue (2014).

12. UNESCO, UNESCO Engineering Report - Engineering the SDGs; 2021.

13. Smith, J.; Tran, A. L.; Compston, P. Review of humanitarian action and development engineering education programmes. European Journal of Engineering Education, 45 (2020).

14. Passino, K. M. Educating the humanitarian engineer. Science and Engineering Ethics, 15 (2009), $577-$ 600 .

15. Sigmon, R. L. Service-Learning: Three Principles. 1979. https://nsee.memberclicks.net/assets/docs/KnowledgeCenter/IntegratingExpEduc/BooksReports/55.\% 20service\%20learning\%20three\%20principles.pdf

16. Vandersteen, J. D.; Baillie, C. A.; Hall, K. R. International humanitarian engineering. IEEE Technology and Society Magazine, 28 (2009), 32-41.

17. Burleson, G.; Austin-Breneman, J. Engineering for global development: characterizing the discipline through a systematic literature review. Proceedings of the ASME 2020 International Design Engineering Technical Conferences and Computers and Information in Engineering Conference. 2020; p V11BT11A011.

18. Delplanque, J. P.; Gosink, J.; Lucena, J. Initiating a program on humanitarian engineering: Rationale, implementation, problems, and perceptions. ASEE Annual Conference Proceedings. 2004. DOI $10.18260 / 1-2--13233$

19. Gosink, J.; Lucena, J.; Moskal, B. Humanitarian engineering at the Colorado schoolof mines: An example of multidisciplinary engineering. ASEE Annual Conference Proceedings. 2003. DOI $10.18260 / 1-2--11871$

20. Colorado School of Mines, HUMANITARIAN ENGINEERING. 2020; https://catalog.mines.edu/graduate/programs/interdisciplinaryprograms/ humanitarianengineering/\# overviewtext.

21. Levine, D. I.; Agogino, A. M.; Lesniewski, M. A. Design for Impact : A Development Engineering Graduate Program at UC Berkeley. DevEng Journal, 2016.

22. University of California Berkeley, Development Engineering Master. https:// developmentengineering.berkeley.edu/program/program-design/.

23. University of Toronto, Centre for Global Engineering. https://cgen.utoronto.ca/.

24. University of South Florida, ENGINEERING FOR INTERNATIONAL DEVELOPMENT. https://www.usf.edu/engineering/cee/graduate/grad-efd.aspx.

25. Smith, J.; Anderson, B.; Brown, N.; Colley, A.; Stoakley, A.; Turner, J. The rise of humanitarian engineering education in Australasia. 28th Annual Conference of the Australasian Association for Engineering Education. 2017.

26. Aardema, B. L.; Churruca Muguruza, C. The Humanitarian Action Qualifications Framework: a quality assurance tool for the Humanitarian Sector. Tuning Journal for Higher Education, 1 (2014), 429-462.

27. Ettridge, M.; Sharma, S. Engineering a Better World: Lessons from the Royal Academy of Engineering's International Development Activities. Journal of International Development, 32 (2020), 85-95.

28. Mendoza-Garcia, J. A.; Ngambeki, I. B.; Behbehani, L. J.; Evangelou, D.; Rao, P.S. C.; Cox, M. F. Defining the knowledge and skills that enable engineers to participate in Public Policy. ASEE Annual Conference and Exposition, Conference Proceedings. 2012. DOI 10.18260/1-2--21141

29. National Society of Professional Engineers, Professional Engineering Body of Knowledge; 2013.

30. Bloom, B. S.; Krathwohl, D. R.; Masia, B. B. Handbook 1 : Cognitive domain / by a committee of college and university examiners: Benjamin S. Bloom, ed. et al.. -1956. - 207 s.; 1956. 